\title{
Can transcendental intersubjectivity be naturalised?
}

Phenomenology and the

Cognitive Sciences

ISSN 1568-7759

Volume 10

Number 1

Phenom Cogn Sci (2009)

10:91-111

DOI 10.1007/s11097-009-9149-

\section{PHENOMINOLOGY}

AND

\section{THE COGNITIVE SCIENCES}

Editors-in-Chief:

Shaun Gallagher and Dan Zahavi

\section{Springer}


Your article is protected by copyright and all rights are held exclusively by Springer Science+Business Media B.V.. This e-offprint is for personal use only and shall not be selfarchived in electronic repositories. If you wish to self-archive your work, please use the accepted author's version for posting to your own website or your institution's repository. You may further deposit the accepted author's version on a funder's repository at a funder's request, provided it is not made publicly available until 12 months after publication. 


\title{
Can transcendental intersubjectivity be naturalised?
}

\author{
Joel Smith
}

Published online: 15 December 2009

(C) Springer Science+Business Media B.V. 2009

\begin{abstract}
I discuss Husserl's account of intersubjectivity in the fifth Cartesian Meditation. I focus on the problem of perceived similarity. I argue that recent work in developmental psychology and neuroscience, concerning intermodal representation and the mirror neuron system, fails to constitute a naturalistic solution to the problem. This can be seen via a comparison between the Husserlian project on the one hand and Molyneux's Question on the other.
\end{abstract}

Keywords Husserl · Intersubjectivity · Molyneux's Question · Intermodal representation

In the fifth Cartesian Meditation, Husserl presents an account of intersubjectivity within the context of transcendental phenomenology. As is well known, Husserl's positive account has been subject to a number of searching criticisms. ${ }^{1}$ Perhaps the most influential of these is what I shall refer to as the problem of perceived similarity. This problem is not answerable from within Husserl's self-imposed theoretical confines, or so I shall argue. However, recent work in developmental psychology and neuroscience, concerning intermodal representation and the mirror neuron system, might be thought to provide the basis of a naturalistic solution to the problem of perceived similarity. ${ }^{2}$ After assessing the empirical evidence, I shall argue that the resulting naturalistic view is not really a theory of intersubjectivity at all, at least not as Husserl would have understood it. This can be seen via a

\footnotetext{
${ }^{1}$ See, for example, Schutz (1970).

${ }^{2}$ See, for example, Gallagher (2005a, b). Gallagher is interested in a number of issues that are not my concern here, such as whether a suitably naturalised Husserlian account presents an alternative to both theory and simulationism concerning the question of mental state attribution. Thus, my intention is not to present a critique of Gallagher's view but rather of a certain view that might be drawn from his work.
}

\section{J. Smith $(\bowtie)$}

Philosophy, Social Sciences, University of Manchester, Manchester M13 9PL, UK

e-mail: Joel.smith@manchester.ac.uk 
comparison between the Husserlian project on the one hand and Molyneux's Question on the other. I conclude that not only does Husserl's transcendental account fail on its own terms but also that the prospects of naturalising it are poor. ${ }^{3}$

\section{Intersubjectivity and transcendental phenomenology}

Husserl's account is an attempt to describe how the sense alter ego (other I) is constituted from within transcendental subjectivity. Amongst other things, this involves saying what is it to have an experience as of another. Or, to put it in other words, it involves giving the necessary and sufficient conditions of having an experience as of another. ${ }^{4}$ Given the supposition that for Husserl the perceptual experience as of another has conceptual content, ${ }^{5}$ this question is closely related to the question of what are the necessary and sufficient conditions for possession of the concept alter ego. ${ }^{6}$

Husserl's answer to this question is constrained by a number of theoretical commitments. It must be arrived at without violating (1) the transcendental reduction, (2) the eidetic method, and (3) what I shall refer to as the noncircularity constraint.

The transcendental reduction, most significantly, involves the bracketing of the "general positing of the natural attitude" (Husserl 1982, Section 30). That is, it involves bracketing the tacit acceptance of the actuality of the objects of our intentional states. Transcendental phenomenology must proceed without relying on this tacit acceptance and without relying on anything that essentially depends on this acceptance. On Husserl's view, this means bracketing the results of the positive sciences, all of which depend on the assumption that the world of intentional objects actually exists (Husserl 1982, Section 32.).

The eidetic reduction brackets contingencies allowing the transcendental phenomenologist to make judgements that claim essential necessity. On Husserl's view, this is achieved via the method of variation in the imagination, whereby the phenomenologist employs imaginary variations on actual intentional states and their objects in order to determine their essence (Husserl 1962, Section 9a.). Husserl sees this as different in kind from the methods of the empirical, but not the pure, sciences.

\footnotetext{
${ }^{3}$ My interest is limited to the account presented by Husserl in Cartesian Meditations. I will not discuss the, somewhat different, accounts of intersubjectivity that he presents elsewhere. There are two main reasons for this. First, this paper is not an exercise in Husserl scholarship. My primary aim is not to get Husserl's considered view right but to assess the prospects for a specific view put forward by Husserl in Cartesian Meditations. Second, the account in Cartesian Meditations has the virtues of being clear and relatively self-contained. It is thus susceptible to analysis and critique within the present limitations of space. This is not true of Husserl's views on intersubjectivity considered as a whole.

${ }^{4}$ This is controversial as the goal of Husserl's project in the fifth meditation might be described in a number of ways. Since my concerns are not primarily exegetical, I will not defend this claim here. For an understanding of Husserl's eidetic method as akin to conceptual analysis, see Zahavi (2003, pp.38-39). I take it that the goal of such an analysis is to provide conditions that are both necessary and sufficient for the application of the concept in question.

${ }^{5}$ For a very useful discussion of Husserl's views regarding such matters, see Mulligan (1995).

${ }^{6}$ Putting things the way I have, Husserl's question has close affinities with that addressed in Peacocke (1984). This is noted by Peacocke who also claims that their answers are not dissimilar (Peacocke 1984, p.106, n. 10)
} 
The non-circularity constraint demands that an account of the constitution of a particular sense must not make ineliminable reference to subjective states that have that sense in their content (or whose content is founded on-has as a necessary condition - that sense). In the case at hand, there must be no reference to intentional states either containing or founded upon states that contain the sense alter ego.

In the fifth meditation, Husserl presents himself as being concerned to answer what he refers to as the problem of transcendental solipsism. Transcendental solipsism is not the view that I am the only existent subject. Rather, it is the view that the sense alter ego is not explicable from within transcendental subjectivity. According to Husserlian transcendental phenomenology, a sense $S$ can only be legitimated by showing how intentional states with $S$ in their content can be constituted within transcendental subjectivity. If such a thing is not possible, then $S$ is seen to be illegitimate. The problem of transcendental solipsism is the problem of showing that and how this is not the case for the sense alter ego. To avoid transcendental solipsism, Husserl must show, in a non-circular way and within the confines of the transcendental reduction and the eidetic method, what it is to have the sense alter ego. This is to be done by tracing the sense alter ego to a more basic, founding, level of intentional states which serve to make it possible.

Husserl recognises that the case of intersubjectivity poses an apparent difficulty for this procedure (Husserl 1960, Section 42.). For once we have effected the transcendental reduction, I am barred from relying on anything beyond my own intentional states and objects. The building blocks with which to show something to have legitimate sense are my own experiences and the world as it is for me. But it is hard to see how such materials can be employed to successfully account for the sense alter ego since the alter ego is precisely something that escapes the reach of my own experience. It is not merely that the alter ego transcends my experience, as do all worldly objects, rather it is that which itself has a world and which is experientially inaccessible to me.

Whether or not this is a serious worry, what is clear is that the problem of transcendental solipsism is of particular concern for Husserl, given his views on objectivity. He takes the view that the sense objective is necessarily dependent on the sense intersubjective since, of necessity, for something to be objective is, in part, for it to be public. ${ }^{7}$ Thus, if transcendental phenomenology cannot provide an adequate analysis of intersubjectivity, neither can it, on Husserl's view, account for objectivity. And one might be tempted to regard the fact, if it turned out to be one, that transcendental phenomenology cannot give sense to the notion of objectivity as a reductio of that research programme.

The purported link between intersubjectivity and objectivity allows us to see one of the respects in which, on Husserl's view, intersubjectivity is transcendental. On this picture, intersubjectivity is a necessary condition of objectivity. Or, more accurately, a subject could not be in states with the content objective if they could not be in states with the content alter ego. And, of course, describing the conditions necessary for an experience as of an objective world, or for a conception of objectivity, is a significant theme of transcendental philosophy.

\footnotetext{
${ }^{7}$ This formulation is significantly weaker than the claim that objectivity just is public, or intersubjective, agreement.
} 
If intersubjectivity is a necessary condition for the possibility of objectivity, then intersubjectivity is transcendental. But there is another sense in which Husserl's account of intersubjectivity might be called transcendental. This is that the Husserlian project involves giving an account of the conditions necessary for having the sense alter ego to be achieved by tracing the sense back to a more fundamental level of intentional experience and thus legitimating, or validating, it. This is perhaps helpfully considered as a phenomenologically oriented variant on the Kantian method of transcendental deduction. A sense, or concept, is shown to be legitimate, that we have a right to its employment, by showing a priori that it has an application to experience. ${ }^{8}$ Senses that purportedly transcend the limits of possible experience are deemed illegitimate. This second sense in which Husserl's account of intersubjectivity is transcendental is clearly more general than the first and may hold even if Husserl is wrong about the necessary connection between intersubjectivity and objectivity.

\section{Husserl's account in the fifth Cartesian Meditation}

Husserl's account of intersubjectivity in the fifth Cartesian Meditation proceeds via a new "primordial reduction" and the resulting "sphere of ownness" (Husserl 1960, Section 44). The primordial reduction is to be undertaken when the transcendental reduction is already in place. It involves abstracting away from all experiences as of an alter ego and all those that constitutively depend on such. Given Husserl's view that objectivity depends on intersubjectivity, this means abstracting away from the objectivity of the objects of experience. That is, once the primordial reduction has been effected, what are to be considered are not objects with the "experiential sense of thereness-for-everyone" (ibid, Section 43) but objects considered merely as the correlates of my own intentional experiences. This is the sphere of ownness. ${ }^{9}$ Of course, this "my own", the "own" of the sphere of ownness, does not have the sense of the objective entity JS but rather the transcendentally, eidetically and primordially reduced ego: the transcendental ego.

The question that Husserl then poses is how, given only the materials available from within the sphere of ownness, we can account for the ego's having experiences as of an alter ego. Or, as Husserl puts it,

How can my ego, within his peculiar ownness, constitute under the name, "experience of something other", precisely something other-something, that is, with a sense that excludes the constituted from the concrete make-up of the sense-constituting I-myself, as somehow the latter's analogue? (Husserl 1960, Section 44)

\footnotetext{
${ }^{8}$ See Henrich (1989). There are, of course, significant questions to be answered concerning the precise meanings of both 'application to experience' and 'legitimate'. Roughly, in the present context, I take the project to be to show that the concept alter ego is a coherent one, not that there is anything that falls under it. This is not to say that Husserl is unconcerned with the latter question. The question whether transcendental methods can provide a satisfactory answer to the quid juris goes right to the heart of the viability of transcendental philosophy.

${ }^{9}$ As is well known, Husserl contradicts himself in his description of the sphere of ownness. See, for example, the discussion in Smith (2003, pp. 215-220). What I am referring to as "the sphere of ownness" is that for which Smith reserves the term "the solipsistic sphere".
} 
The answer, according to Husserl, lies in a combination of the peculiar way that one object is given to me, namely my own body and its perceived similarity to certain other perceived objects, that is, the bodies of others.

I experience my body in a way that I experience no other thing. I am aware of my own body as a lived body (Leib). In particular, I feel sensations in my body and am aware of it as something with which I can act in an immediate way. This singles out my own body from everything else within experience. As Husserl says,

if I reduce other men to what is included in my ownness, I get bodies [Körper] included therein; if I reduce myself as a man, I get "my animate organism" [Leib] and "my psyche", or myself as a psycho-physical unity. (Husserl 1960, Section 44)

My body is given to me with a particular sense within the sphere of ownness. But now when I observe the body of another, I perceive a similarity between my own and the other's body. My own body, being continually present, is experienced as one of a "pair" with the other's body. When this occurs, there is what Husserl refers to as

an overlaying of each with the objective sense of the other....As the result of this overlaying, there takes place in the paired data a mutual transfer of sensethat is to say: an apperception of each according to the sense of the other. (Husserl 1960, Section 51)

On Husserl's view, this sort of pairing is a form of association that is a quite general phenomenon. With regards to the pairing of the other's body with my own, Husserl's claim is that the experienced sense of my own body as lived is transferred onto the body of the other. I then apperceive that other body as a lived body. Since those qualities that constitute the body's livedness cannot be experienced directly by me, but are only ever apperceived, with respect to the other's body, I experience it as another lived body. That is, since I cannot live the other's body, I experience it as the lived body of another, as another psycho-physical unity, as an alter ego.

Husserl takes his account to be a description of how it is that the transcendental ego can intend others as other egos. Thus, he speaks, taking on the Leibnizian term, of an "open community of monads, which we designate as transcendental intersubjectivity" (Husserl 1960, Section 56). A monad is "the ego taken in full concreteness" (Husserl 1960, Section 53) with respect to its intentional experiences. It is thus a particular instance of the transcendental ego, with the latter conceived as "the all embracing eidos, transcendental ego as such" (Husserl 1960, Section 34). Husserl sometimes speaks of the "de facto transcendental ego" (Husserl 1960, Section 36) which is, perhaps, best understood as another way of referring to the monad, i.e. it is a particular realisation of the transcendental ego. But now, the question arises as to whether transcendental intersubjectivity is to be thought of as a community of transcendental egos as such (the essence transcendental ego) or a community of de facto transcendental egos (monads).

In his influential critique of Husserl's account of transcendental intersubjectivity, Schutz asks, I take it rhetorically,

what sense would it make to speak of intersubjectivity with reference to the one and unitary Eidos "transcendental ego at large," that is, to speak of transcendental not mundane intersubjectivity? (Schutz 1970, p. 79) 
Schutz's point is well made. If we mean by 'transcendental ego' the ego's essential structure, then it seems senseless to suggest that there could be a plurality of transcendental egos. But it is not clear what else we could mean given that the analysis of intersubjectivity is to be undertaken within the context of both the phenomenological and eidetic reductions.

Of course, what Husserl refers to in the above quotation is a community of monads. And the concept of such a community is not senseless in this way. So, perhaps we should understand Husserl's thought in something like the following way. It belongs to the essential structure of the ego to belong, or be capable of belonging, to a community of egos. Thus, the transcendental ego can be intentionally directed to others. And it is natural, if perhaps not ultimately very helpful, to think of this as involving a community of transcendental egos, for if the transcendental ego intends an alter ego, then surely it is an alter transcendental ego. That is, the ego that one is intentionally directed towards as other is of the same sort as the ego itself, transcendental.

Regardless of whether or not Husserl's talk of a community at the transcendental level really makes sense, there is, as mentioned above, reason enough to think of his account of intersubjectivity as a transcendental one. There is, therefore, a clear sense according to which, in evaluating his account, we are evaluating a transcendental account of intersubjectivity.

As I have described it, it is unclear whether Husserl's account of intersubjectivity in the fifth Cartesian Meditation is intended as a static or a genetic analysis. In fact, this lack of clarity is to be found in the text. ${ }^{10}$ On the one hand, Husserl is explicit that the account is static. ${ }^{11}$ On the other, the concept of pairing only has a meaning within the context of a genetic analysis, and a great deal of Husserl's language is explicitly temporal. ${ }^{12}$ Of course, it is possible that this is merely a failure to clearly distinguish genetic from non-genetic elements in an account that combines both. On such a view, the account would contain some proposals as to what must be the case at $t$ for a subject to enjoy an experience at $t$ as of an alter ego and also some proposals as to what must have been the case prior to $t$ for that to be so. Whatever might be the correct way to interpret Husserl on this question, this is the view I shall take, leaving it as an open question which are the static and which are the genetic elements.

\section{The problem of perceived similarity}

Husserl's account of intersubjectivity relies on the idea that within the sphere of ownness, there is a perceived similarity between the other's body and one's own.

\footnotetext{
$\overline{{ }^{10} \text { See, for example, Lee (2002). }}$.

11 "Here it is not a matter of uncovering a genesis going on in time, but a matter of 'static analysis" (Husserl 1960, Section 48).

${ }^{12}$ Especially in his discussion of "primal instituting" (Husserl 1960, Section 50). It is unclear to me how Husserl's use, in the fifth meditation, of the concept of pairing can be made consistent with Zahavi's claim that "Husserl does not seem to advocate the thesis that the primordial level has a temporal priority compared with the intersubjective level" (Zahavi 2001, p. 27).
} 
However, this idea has long been found problematic. ${ }^{13}$ Consider the visual appearance of the other's body as compared with the visual appearance of one's own body. Unlike the other's body, one only ever perceives one's own body from one angle. Although one can adopt a varying perspective on some of one's body parts, one's hands for instance, this is not a possibility with respect to one's body as a whole. Further, one never sees one's own face, except occasionally the tip of one's nose. Indeed, in the majority of one's experience, one hardly sees one's own body at all. Not only that, one's own body is necessarily experienced as here whilst the other's body is necessarily experienced as there. These dissimilarities suggest that visual appearance would be unlikely to ground a perceived similarity between one's own and the other's body.

The response that one can perceive a similarity between the other's body and one's own body as reflected in a mirror will not convince. For one's reflected body appears as the body of another, that is it is not immediately experienced as a lived body. This is why, in Duck Soup, Groucho can wonder whether he sees his own reflection or somebody else. ${ }^{14}$

Of course, Husserl was well aware of this problem. He suggests that the other's body is perceived to be similar not to one's own body as it actually appears but to how one's own body would appear if it were where the other's body is. As Husserl puts it, "It brings to mind the way my body would look 'if I were there"" (Husserl 1960, Section 54). But, again, this can't be right since were I 'over there', then my body would look exactly as it now looks since I would be seeing it from over there. Thus, what is required is that the other's body be paired with my body as it would look from here if it were over there. In this way, the location of the body is dissociated from the point of view from which it is seen. ${ }^{15}$

This view, however, faces the task of showing how a conception of how my body would look if it were over there but perceived from over here could be constructed from the meagre materials available within the sphere of ownness. In particular, how I can come to conceive of my body as a material thing upon which different perspectives can be taken given that, necessarily, I have only one perspective on it. ${ }^{16}$ Might it not be that a conception, and experience, of my own body as a movable physical object is only available given an awareness of how I look to another? ${ }^{17}$ If such were the case, Husserl's account of intersubjectivity would be circular.

\footnotetext{
${ }_{13}$ See, for example, Schutz (1970, pp. 63-64).

${ }^{14}$ Compare Husserl, "Obviously it cannot be said that I see my eye in the mirror, for my eye, that which sees qua seeing, I do not perceive. I see something, of which I judge indirectly, by way of "empathy," that it is identical with my eye as a thing (the one constituted by touch, for example) in the same way that I see the eye of an other." (Husserl 1989), p. 155, n. 1.

${ }^{15}$ Given the obvious fact that the congenitally blind do arrive at an intersubjective awareness, the use of the visual modality must be inessential. I shall simply assume that Husserl's account could be rewritten in terms of other sensory modalities. Husserl suggests such a thing, for the case of auditory experience, in Husserl (1989), p. 101, n. 1.

${ }^{16}$ Merleau-Ponty goes so far as to say that this disqualifies one's body as an object of perception, "an object is an object only in so far as it can be moved away from me, and ultimately disappear from my field of vision. Its presence is such that it entails a possible absence. Now the permanence of my own body is entirely different in kind...it defies exploration and is always presented to me from the same angle" (Merleau-Ponty 1962, p. 90).

${ }^{17}$ As is argued in Reynaert (2001).
} 
This argument would need to be presented in more detail. But, in any case, there is reason to think that no account that appeals solely to how one's body is visually presented is going to be satisfactory. For in order for pairing to do the work that Husserl demands of it, it needs to be the case that one is immediately aware of those qualities that make up the livedness of one's own body. And this is not true of one's own body as presented in vision. Just as one's body seen in a mirror is not immediately given as lived, neither is one's own body as seen in ordinary experience. One could very well mistake one's own body for the body of someone else, or vice versa, in appropriately confusing circumstances. ${ }^{18}$ Since one's body, as visually perceived, is not immediately given as lived, its pairing with other bodies will not help to found the apperceived livedness of the other's body.

However, we are, of course, perceptually aware of our bodies in ways other than vision. Through proprioception and kinaesthesia, we have a sense of the shape, size, orientation and movement of our bodies. Bodily sensations are experienced as spatially located in or on one's body. The sense of touch gives one an awareness of the shape and solidity of one's body, just as it gives one an awareness of the shape and solidity of worldly objects. In all of these ways, sometimes referred to collectively as 'bodily awareness', it might be argued that we have a sense of our own bodies as physical objects. ${ }^{19}$ This sense, then, might ground a conception of what my body would look like, from here, if it were over there.

But there is a potential problem with any account that employs this sort of formulation for we cannot read the above as "what my body would look like to another, from here, if it were over there" since that would render the account circular. Then again, if we read it as "what my body would look like to myself, from here, if it were over there", it sounds as though what we have described is incompatible with Husserl's view that my 'here', the zero point of orientation of perceptual experience, is necessarily given by the experienced location of the lived body. As such, it is not clear that the Husserlian account can make use of the formulation.

Perhaps the resolution of this difficulty is simply to drop the view that my 'here' is necessarily given by the experienced location of the lived body. The problem with such a suggestion is that it deprives Husserl of the materials with which he can defuse (or preempt) a well-known objection to the effect that the Husserlian account, and any broadly analogical account, cannot account for the fact that the body of the other is experienced as an other's body. ${ }^{20}$ That is, it cannot explain why the perceived distal body is not experienced as an extension of one's

\footnotetext{
18 This point is closely related to the claim that visually grounded self-ascriptions of bodily predicates are not immune to error through misidentification relative to the first person pronoun. On immunity to error, see Evans (1982).

${ }^{19}$ See Martin (1995) for a useful discussion of bodily awareness. Bodily awareness, as understood here, incorporates both elements of the body image, characterised by Gallagher as, "a system of perceptions, attitudes, and beliefs pertaining to one's own body" (Gallagher 2005a, p. 24), and any experiential elements that may be associated with the body schema, characterised by Gallagher as, "a system of sensory motor capacities that function without awareness or the relevant perceptual monitoring" (ibid.).

${ }^{20}$ For what is essentially this objection posed to analogical accounts in general, see Scheler (2008, pp. 240-241).
} 
own body, and the appresented ego experienced as an extension of one's own ego. If nothing in the account can explain the otherness of the other's body, the alterity of the alter ego, then the account has surely failed in its primary task. The answer to the objection is that the otherness of the other's body is accounted for by the fact that one's own lived body is necessarily experienced as 'here' whilst the distal body is experienced as 'there'. Thus, it is experienced as a body other than one's own. ${ }^{21}$ This answer, however, would be unavailable if the Husserlian were to drop the apparently troublesome view that my 'here' necessarily travels with the experienced location of my lived body.

Maybe the answer is to adopt an impersonal, subjectless reading of the formulation. Thus, the Husserlian could maintain that the other's body looks similar to how one's own body would look, from here, if it were over there. Here, there is reference both to how one's body looks and to its being given from a point of view. However, there is no suggestion as to whom it is given. The experiences mentioned are, on this view, anonymous. $^{22}$ On such a reading, there is no impossibility, and the account is not circular. Rather, what is required for the Husserlian account of intersubjectivity is an impersonal, subjectless conception of seeing (or experiencing) - a conception of seeing that is not tied to any particular subject.

However, even if this view avoids circularity, it might be thought that it merely pushes back the hardest problem that an account of intersubjectivity has to answer. For the question now becomes how it could be that, from within the sphere of ownness, one could arrive at a subjectless conception of conscious states such as seeing. This might seem like an especially hard question to answer since their sphere of ownness limits one to precisely one's own conscious states. One might suggest that coming to a subjectless conception of a conscious state on the basis of one's own conscious states is no easier than, from the same basis, coming to a conception of a conscious state enjoyed by another. As Wittgenstein famously remarked,

If one has to imagine someone else's pain on the model of one's own, this is none too easy a thing to do: for I have to imagine pain which I do not feel on the model of the pain which I do feel. (Wittgenstein 1953, Section 302)

The relevance of this might be made clearer by adjusting Wittgenstein's emphasis, thus: I have to imagine pain which $I$ do not feel on the model of the pain which $I$ do feel. My suggestion here is not that this is a challenge that cannot be met. Rather that if this challenge can be me, then we are already most of the way towards an account of intersubjectivity, with little of the heavy lifting being done by Husserl's account. ${ }^{23}$ This route out of the present difficulties places a dark cloud over the claim of

\footnotetext{
${ }^{21}$ See Smith (2003), p. 227.

${ }^{22}$ This way of putting things recalls Merleau-Ponty: "if I wanted to render precisely the perceptual experience, I ought to say that one perceives in me, and not that I perceive" (Merleau-Ponty 1962, p. 215). The related claim that bodily awareness does not have first-personal content is argued for in Smith (2006). ${ }^{23}$ This point also explains what is wrong with the suggestion that the complexities of Husserl's account are unnecessary, a conception of intersubjectivity being available to any subject with a conception of experience and a capacity to reason with identity, negation and existential generalisation. For the question remains, how does the subject arrive at a conception of experience that is not a conception of their own experience.
} 
Husserl's account to be genuinely informative. It is worth, then, considering another way of answering the problem of perceived similarity. ${ }^{24}$

\section{A naturalistic solution: Intermodal representation}

Bodily awareness might be brought into the account of intersubjectivity in two different ways. First, it might, as above, be proposed as a way of founding the constitution of one's own body as a physical object. This would be in the service of defending the claim that a conception of what my body would look like from here, if it were over there is available from within the sphere of ownness. Second, it might be thought to render superfluous that particular troublesome convolution in Husserl's account for it might be suggested that the visually appearing body of the other is perceived as similar to one's own body as experienced through bodily awareness.

On the face of it, this latter suggestion might seem to have little to recommend it for it is equally, if not more, difficult to see how a perceived similarity could bridge two sensory modalities than it is to see how the other's body could be perceived as similar to one's own body as it is actually seen. Indeed, this is essentially what McGinn (1984) sees as the most taxing version of the problem of other minds-how can it be that we form a unitary concept of, say, pain based upon the inner experience of our own pains on the one hand and the visual experience of pains in others on the other? ${ }^{25}$

However, it is just this view, that the other's visually perceived body and one's own body, given through bodily awareness are directly perceived as similar, that is suggested by the following comment from Gallagher,

Scheler notes that the way my body is experienced by me (e.g., more through kinesthetic proprioception than through exteroceptive or visual perception) is quite different from the way the body of another person is perceived by me (exclusively through exteroception). If this objection holds, it would challenge the insights of Husserl mentioned earlier. But this objection is questionable. Developmental studies have shown that intermodal perception is operative from the very beginning of life.... What I see is automatically registered in a code that is common to other sense modalities, including kinaesthesia and proprioception. So when I see the other's body moving in a certain way, I have a kinesthetic-proprioceptive sense of what that is like. (Gallagher 2005b, pp. 101-102)

\footnotetext{
${ }^{24}$ The problem of perceived similarity is not the only problem faced by Husserl's account. Another, much discussed, problem revolves around the claim that the sphere of ownness is an empty notion since experience is intersubjective through and through. One way of fleshing this thought out is that the other's body is given as an object, thus given in adumbrations, yet the notion of a horizon, essential to something's being so given, is itself an intersubjectively loaded notion. Thus, intersubjectivity is more fundamental than objectuality. Given this, the account in Cartesian Meditations gets things back to font or, at least, cannot tell the whole story. This line of thought is presented in Zahavi (2001, pp. 39-52). However, as Zahavi sees matters, this is not so much an objection to Husserl's account but an objection to a misguided way of reading Husserl.

${ }^{25}$ Also see Davidson (1987).
} 
The claim here is that Husserlian pairing is realised at the level of 'a code that is common' to both vision and bodily awareness. The visual experience as of another's body behaving in some way is sufficient to give me a sense of how it would feel to be doing the same. This fact could then ground the transfer of the sense lived body from my own body, as given in bodily awareness, to the body of the other.

Gallagher's account is interesting to pursue since it suggests a way of naturalising Husserl's account of intersubjectivity, a way that solves the problem of perceived similarity. Gallagher's proposal would also avoid any difficulties that might be associated with the availability, within the sphere of ownness, of a conception of one's body as something that would look, from here, a certain way if it were over there. It would also avoid Scheler's problem of the otherness of the other's body since one could continue to maintain that $m y$ body is necessarily experienced as here.

However, these gains are made by recourse to empirical psychological work, and this, from a Husserlian point of view, appears to involve a naturalistic violation of both the phenomenological and eidetic reductions. ${ }^{26}$ However, the account could still qualify as transcendental in the sense of forming part of an account of the necessary conditions of objectivity for there is no reason to suppose that the intentional states appealed to in the naturalised account would presuppose a notion of objectivity and so, on Husserl's view, of intersubjectivity. Of course, the empirical work drawn upon will almost certainly presuppose a certain conception of objectivity. But it does not follow from this that the content of the lower level intentional states that constitute the sense alter ego either contain or constitutively depend upon the sense objective.

Furthermore, it is still an open question whether the account could legitimate the concept alter ego by tracing it back, in a non-circular way, to a more fundamental level of intentional experiences. That is, the account may still identify those experiential conditions that make the experience of an alter ego possible, thus also counting as transcendental in that sense. The account would no longer be entirely a priori, and for that reason, one may baulk at referring to it as transcendental. Of course, if a priority is a condition of transcendental status, and naturalistic theories rely essentially upon empirical science, then no naturalistic theory could qualify as transcendental. The interesting question is whether a naturalistic theory could play the same role as a transcendental one. That is, could a naturalistic account of intersubjectivity legitimate the sense alter ego? To answer this question, one would need to know the reason for the traditional demand that such legitimation be a priori. This is a question that raises a number of complex issues concerning the nature of transcendental philosophy, and it is not one that I shall attempt to answer here. The view that I am arguing for in this paper is that even if there is no generally applicable reason to reject naturalised transcendental accounts out of hand, there are significant problems specific to the naturalisation of Husserl's account of intersubjectivity that is currently under consideration.

\footnotetext{
${ }^{26}$ I use 'naturalisation' in a rather loose way. I simply assume that an account of the conditions of enjoying a certain type of experience that makes ineliminable reference to the results of empirical psychology will count as naturalistic according to some reasonable conception.
} 


\section{Neonate imitation and the mirror system}

Assuming for the time being that the intermodal code postulated by Gallagher would indeed plug a leak in the Husserlian account, albeit at the expense of the phenomenological and eidetic reductions, the question that needs to be answered is what empirical evidence there is for it. Gallagher bases his claim primarily upon the evidence indicating a capacity for invisible imitation in neonates. He cites work appearing to show that neonates as young as $42 \mathrm{~min}$ can imitate visually perceived mouth opening and tongue protrusion. ${ }^{27}$ This imitation is 'invisible' since the part of their own bodies with which these neonates imitate, their mouth and tongue, is one that they cannot see, indeed is one that they have never seen. Following Meltzoff and Moore (1997), Gallagher argues that this capacity is best explained by the postulation of an intermodal system in which visual and kinesthetic-proprioceptive information is represented in a common way.

For the infant to be able to imitate a displayed facial gesture, it must be able to translate a visual display into its own motor behaviour. In an intermodal system, proprioception and vision are already in connection with each other. In certain cases, what I see automatically gets translated into a proprioceptive sense of how to move. (Gallagher 2005a, p. 75)

Gallagher further suggests that this intermodal system of representation is realised, at least in part, in the so-called mirror system. This is a system of 'mirror neurons' first discovered in area F5 of the ventral premotor cortex of macaque monkeys and now also believed to exist in Broca's area in the human brain. ${ }^{28}$ Mirror neurons fire both when a particular action is performed and when that same action is observed being performed by another. Although there is no direct evidence for the activation of mirror neurons in neonates, Gallagher proposes the following as a 'reasonable hypothesis',

when the neonate sees another person perform a specific motor act, for instance a tongue protrusion, the visual stimulus initiates the firing of the same mirror neurons that are involved in the infant's own performance of that motor act. (Gallagher 2005a, p. 77) ${ }^{29}$

The intermodal code postulated by Gallagher is brought into play as an answer to the problem, for the Husserlian account of intersubjectivity, of perceived similarity. Gallagher claims that the perceived similarity between the other's visually perceived body and one's own proprioceptively perceived body can be accounted for by this account of 'intermodal perception'.

Thus, the objection to the Husserlian account is answered naturalistically. However, the evidence for neonatal imitation is not as clear-cut as Gallagher's argument suggests. ${ }^{30}$ It has been claimed that invisible behavioural matching reliably occurs only with respect to tongue protrusion (Anisfeld et al. 2001). If only one

\footnotetext{
${ }^{27}$ See Meltzoff and Moore (1977).

${ }^{28}$ See, for example, Rizzolatti et al. (2001).

29 To the best of my knowledge, there is no evidence either for or against the claim that observed tongue protrusion activates the human mirror system either in monkeys or in humans.

${ }^{30}$ A useful discussion of scepticism about strong claims concerning neonatal imitation is Welsh (2006).
} 
movement is matched, a number of non-imitative explanations become possible, one being that tongue protrusion is an arousal response that occurs when the infant sees an exciting active face. Since it has also been found that tongue protrusion occurs when a variety of non-human objects are shown to infants, there is indeed some reason to believe that the movement serves some non-imitative, perhaps exploratory, purpose. $^{31}$

These sceptical challenges to the existence of neonatal imitation are serious. However, the received view is indeed that such imitation does take place. And, of course, even if it does turn out that there is little robust evidence in favour of neonate imitation, that would not show that the intermodal code hypothesis is false or unmotivated since there may well be other reasons to postulate such a code.

Supposing that the sceptical challenge can be answered, one might still wonder whether the intermodal code solution really remains in any way distinctively Husserlian for it is often argued that the existence of neonate imitation is evidence that the infant has an innate grasp of the distinction between itself and others like it. $^{32}$ This is certainly a consequence that Gallagher accepts,

The newborn infant's ability to imitate others, and its ability to correct its movement, which implies a recognition of the difference between its own gesture and the other's gesture, indicates a rudimentary differentiation between self and non-self...one's earliest experiences include a sense of self and of others. (Gallagher 2005a, pp. 83-84)

But what now has become of the sphere of ownness? If, from birth, the infant can have experience as of an alter ego, then there appears to be no room for the sphere of ownness understood as a developmental phase taking place prior to the onset of intersubjective experience. Although this might sound like an outright rejection of the Husserlian account of intersubjectivity, it is not clear that it is for the Husserlian account might be understood primarily as static, with the sphere of ownness conceived merely as an abstraction from actual, intersubjective experience, not as a stage of normal human development. ${ }^{33}$

Perhaps a more serious question about Gallagher's naturalistic solution to the perceived similarity problem concerns exactly what is imitated. According to Gallagher, what is imitated is another's action and expression, and he points out that there is evidence that mirror neuronal activity is correlated with action rather than motor behaviour (Gallagher 2005a, pp. 82-83). If this is correct, then it appears to violate Husserl's non-circularity constraint. The account of the constitution of the sense alter ego makes reference to a perceptual awareness of the other's subjective states, which awareness presumably depends upon an awareness of the other as another subject. As such, Gallagher's proposal fails to offer an account of what it is to have an experience with the sense alter ego for the availability of such an experience is presupposed in the proposed view. The Husserlian account requires us

\footnotetext{
$\overline{{ }^{31} \text { See Jones (1996). Jones (2006) }}$ also found that music affects the rate of infant tongue protrusion.

${ }^{32}$ For example, Gallagher and Meltzoff (1996).

33 Although some of the detail of Husserl's account may have to be rejected, for example the discussion of "primal instituting" (Husserl 1960, Section 50). In any case, there is some scepticism as to whether the empirical evidence is sufficient to warrant an innate intersubjectivity. See, for example, Gergely (2004).
} 
to be able to give sense to the suggestion that from within the sphere of ownness, the subject can perceive a similarity between his own and the other's body. Gallagher's use of neonate imitation and the mirror system will only help us here if what is imitated, or what is represented by the relevant mirror neurons, is available from within the sphere of ownness. But on Gallagher's own reading of the empirical evidence, it seems that it is not. Thus, his naturalistic account has really given up on all of distinctive elements of the Husserlian view. It may be a naturalistic theory of intersubjectivity, but it is not a naturalisation of Husserl's theory of transcendental intersubjectivity. And that latter is the present concern. ${ }^{34}$

But perhaps Gallagher is wrong in his appraisal of the evidence concerning what is imitated, and represented by the mirror system. If it could be shown that, in point of fact, bodily behaviour rather than action was implicated, then the account might be saved from the circularity worry.

First, consider mirror neurons. A common view has been that mirror neurons represent the intention of another subject in performing a particular action. ${ }^{35}$ Evidence for this is that mirror neurons do not fire when an action's target object is known to be absent. ${ }^{36}$ It seems that the mirror system distinguishes between actions even though they are instances of the same bodily movement. If this is correct, then we have the circularity problem. ${ }^{37}$ The perceived similarity supposedly realised in the mirror system is not one that is available from within the sphere of ownness.

With respect to neonate imitation, the empirical evidence suggests a rather different picture. According to Meltzoff and Moore (1997), early neonate imitation is of what they refer to as 'organ relation end state'. This is the position of the bodily organs reached via bodily movement. Only at 18 months do infants imitate the intentions of others. When 18-month-olds observe someone trying, but failing, to

\footnotetext{
34 This problem cannot be resolved by appealing to a static conception of the Husserlian account, as was the case with the concern over innateness. The problem here is not one of the temporal priority of the states appealed to but of their content. As such, the problem applies to static and genetic analyses alike.

35 Jacob (2008) is sceptical about this claim. However, Jacob's own view that mirror neuron activity presupposes that the subject has a prior representation of the other's intention would not offer any way out of the present difficulty. Also see Borg (2004) for a useful corrective to implausibly strong readings of the claim that the mirror system represents the target's intentions.

${ }^{36}$ Umiltà et al. (2001). Rizzolatti et al. (2001, p. 667) distinguish between the intention and the meaning of an action, claiming that the evidence only shows the latter is represented. However, their understanding of the meaning of an action, of 'what the agent did', is clearly an understanding of it as intentional. Muthukumaraswamy et al. (2004) report that in humans, although behaviourally equivalent but nonobject-involving actions do activate the mirror system, they do so less effectively than their objectinvolving counterparts. Again, this suggests that the mirror neuron system is responsive to the intention that guides an action.

${ }^{37}$ Not quite. It might be suggested that the mirror system distinguishes between bodily behaviours not in virtue of their guiding intentions but in virtue of their 'goals' where grasping something as a goal need not involve a grasp of it as something engaged in by a subject. A goal might be thought of as behaviour in line with the behaving object's characteristic function. The hand has many functions, one of which is to grasp objects, none of which is to grasp thin air. Thus, the cited evidence might be explained by claiming that the mirror system is sensitive to a bodily activity's goal and can therefore be appealed to from within the restrictions of the sphere of ownness. This is an interesting possibility which might be thought to gain some support from evidence that suggests that robotic actions can stimulate the mirror system (Oberman et al. 2007). However, it is possible that this effect is the result of the observers' anthropomorphising of the robot. The suggestion is also in at least some tension with evidence to the effect that the mirror system is activated by the intentional, but non-goal-directed, tracing of geometrical figures in the air (Fadiga et al. 1995).
} 
perform some action, they can imitate the successful action, the suggestion being that they are aware of, and imitate, what the other intended to do (Meltzoff 1995). In fact, there is some evidence that this kind of completion occurs earlier, at 10 months (Legerstee 2005, pp. 63-70). But whatever turns out to be the correct developmental timetable, there is no suggestion that intentional actions are imitated by neonates. Gallagher is right that intentional actions are imitated, but wrong that this applies to neonates. And it is neonate imitation that is crucial for present concerns since it occurs before the infant has had the opportunity to match visually and proprioceptively experienced movements, say in the mirror. It is thus neonate imitation that provides the best evidence for an 'intermodal code'. It seems, therefore, that according to this evidence, the circularity concern that causes trouble for the mirror neuron evidence does not apply to imitation.

It is not clear which way to turn here. On the one hand, there is evidence that the human mirror system represents intentional action; on the other, there is evidence that at least in neonates, invisible imitation takes place with respect to bodily states rather than intentional action. An initial thought is that Gallagher's speculative 'reasonable hypothesis' linking neonate imitation with the mirror system is questionable. ${ }^{38}$ If so, then mirror neuron activity provides no direct evidence for the 'intermodal code' hypothesis since it may turn out that the mirror system's functioning depends upon a prior learnt association between visually perceived and proprioceptively perceived intentional action. ${ }^{39}$ Whilst this counts as a problem for the letter of Gallagher's account, it might not be such a serious concern for the overall project for there remains the widely accepted evidence for neonate imitation. It seems reasonable to suppose that there is, at least, a good case to be made for the existence of intermodal representation, common to vision and proprioception. ${ }^{40}$

So, whilst the letter of Gallagher's account excludes it as Husserlian since it violates the circularity constraint, an account that appeals solely to the evidence for neonate imitation can avoid this problem. However, in the next section, I raise a problem that affects not just the letter but the spirit of the naturalised Husserlian account in a fundamental way.

\section{Perceived similarity, Molyneux's question and conceptual connections}

There is more than a superficial connection between the problem of perceived similarity and Molyneux's Question. Molyneux's question is whether a congenitally blind person, able to distinguish a cube and sphere by touch, would be able to distinguish them by sight were his sight to be regained. ${ }^{41}$ Molyneux's question raises

\footnotetext{
${ }^{38}$ See Jones (2005) for a trenchant criticism of just this kind of speculation.

${ }^{39}$ For such a claim, see Keysers and Perrett (2004).

40 There is, of course, a great deal of further evidence for 'intermodal perception'. See, for example Schmuckler and Fairhall's (2001) experiments using point light displays and Streri and Gentaz's (2003) experiments concerning the perception of shape. However, in the former, the infants tested were 5 months, easily old enough for learned associations to have been established; in the latter, the perceptions of shape were argued to be intermodal between vision and touch rather than vision and proprioception. Of course, touch and proprioception are not unrelated, and it may be that some of this research turns out to be relevant to the current concerns. I will not pursue that line of thought here, however.

${ }^{41}$ Molyneux's question is quoted in Locke (1975), Book II, Chapter 9, Section 8.
} 
a number of interesting issues, some broadly empirical others more purely philosophical. According to Evans' (1985) influential account, the most significant philosophical issue concerns the identity or diversity of shape concepts derived from the two sensory modalities. Do we have one concept visible square and a distinct concept tangible square, or do we have just the one concept, square, derivable from either modality? We can think of this as a question concerning the unity of perceptually derived spatial concepts. ${ }^{42}$

Earlier, I mentioned McGinn (1984) who poses the question of how it can be that we form a unitary concept of, say, pain based upon the inner experience of our own pains on the one hand and the visual experience of pains in others on the other. The similarity between this and the issue that Evans extracts from Molyneux's question is evident. $^{43}$ One way of thinking about Gallagher's invocation of intermodal perception, in the context of Husserl's theory of intersubjectivity, is as an answer to McGinn's question. We might expect, then, that in the absence of any relevant differences, if the postulation of intermodal representation can solve the problem of perceived similarity, then the postulation of intermodal representation, common to vision and touch, could affirmatively answer Evans' question of the unity of perceptually derived spatial concepts. On the other hand, we might expect reasons to doubt the viability of such an intermodal representation approach to Evans' question to generalise to the problem of perceived similarity. Given this, it is worth spending a little time on the potential for answering Evans' version of Molyneux's question in such a way.

Unsurprisingly, Gallagher takes just such an approach to Molyneux's question. He distinguishes between the empirical and the in principle questions concerning whether a blind person's restored sight would allow them to tell which of two presented objects was a cube and which was a sphere. The straightforward empirical question appears to have been answered negatively by actual cases going back at least to Cheselden's cataract operations in $1728 .{ }^{44}$ However, Gallagher argues that this negative answer can be explained neuroscientifically. He cites empirical work in support of the view that "there is a critical period of three to twelve weeks in early infancy in which visual experience is necessary for the proper formation of ocular dominance columns in the visual cortex....Thus, childhood cataracts, if not removed prior to or early in the critical period, lead to visual deficiencies that remain even after they are removed" (Gallagher 2005a, p. 165). Nevertheless, he argues that if these facts are bracketed, if we imagine a congenitally blind subject who does not suffer the relevant deterioration of the visual cortex, then a positive answer to Molyneux's question would be the right one. The reasons behind this positive answer to the in principle question are that "sense modalities do communicate naturally. Perception is intermodal from the very start....Experience in one sense modality does educate other sense modalities" (Gallagher 2005a, p. 161). And his

\footnotetext{
$\overline{42}$ Although Evans puts things in terms of the derivation of concepts from experience, this is not essential. The point is that we are concerned with observational concepts - concepts that are applicable purely on the basis on the relevant experience.

${ }^{43}$ Indeed, it was reading Evans (1985) that prompted McGinn to formulate the problem in just this way (McGinn 1984, p. 135, fn. 6).

${ }^{44}$ For a useful account of early empirical work, see Morgan (1977, Chapter 2).
} 
reason for believing that is empirical work suggesting an innate intermodal code between vision and touch, evidence of the same sort that is appealed to in the case of the problem of perceived similarity. ${ }^{45}$

But Gallagher's in principle version of Molyneux's question is not precisely the same as Evans' question concerning the unity of perceptually derived shape concepts. The one concerns what the newly sighted person would be able to do, given that he escapes deterioration of the visual cortex; the other concerns the nature of shape concepts. So, supposing that Gallagher is correct about the in principle question, is Evans' question also thereby answered? Evans' view is that it is not. Evans describes the views of two fictional philosophers, $\mathrm{V}$ and $\mathrm{B}$ (the latter being a philosophical cousin of Berkeley). $\mathrm{V}$ holds that the concept square derived from visual experience is the very same concept as the concept square derived from tactile experience. $\mathrm{B}$, on the other hand, distinguishes between the concept visible square and the distinct concept tangible square, each derived from the relevant modality. That is, V holds that the perceptually derived concept square is unified; B holds that it is not. During his discussion of the dispute between V and B, Evans claims that,

far from innateness being an essential ingredient of V's position, it is an element of a perfectly possible variant of B's position. B holds that there is no conceptual connection between tangible square and visible square, but this leaves it open how the move from the visible to the tangible is made. Berkeley held that we learn the connection by experience, but an alternative hypothesis is that the connection is pre-programmed into the brain.... It follows from this that Molyneux's Question is not in fact a crucial experiment in the dispute between $\mathrm{B}$ and $\mathrm{V}$ for although a negative answer would refute $\mathrm{V}$, a positive answer would be consistent both with V's position and with this nativist version of B's position (Evans 1985, pp. 377-378).

Similarly, it may be argued, Gallagher's account is consistent with both V's position and the nativist version of B's position. That is, for all we have yet been told, the intermodal code in which information from both vision and touch is represented is an innate way of making the transition between two distinct concepts. If so, Gallagher's position is consistent with a disunified view of perceptually derivable shape concepts.

A similar point can be made in the context of Husserl's theory of intersubjectivity. There, the problem was to show that the concept alter ego is legitimate. A condition of success in this project is that the concept ego does not split into that of introspectible ego and that of observable ego, with no conceptual connection unifying the two. That is, with only an innate tendency or disposition to move between the two. But on the intermodal perception account, the transition between proprioceptive awareness of my bodily activity and visual awareness of another's bodily activity may indeed be just such a non-conceptual transition. And if that is so, the account will fail as an account of intersubjectivity for it will not be an account of intersubjectivity at all. An account of intersubjectivity must legitimate the concept alter ego, but unless the concept of a subject of experience is unified, the other will

\footnotetext{
$\overline{{ }^{45} \text { In particular, Gallagher appeals }}$ to Meltzoff and Borton (1979) and Streri and Gentaz (2003).
} 
not be an alter ego at all, at least not in the sense that I am an ego. It will be other, but it will not be another me.

How might one respond to this argument from 'conceptual connections'? An initial thought might be to argue that the intermodal transfer of information from vision to proprioception is, in fact, realised on an experiential level. Indeed, Gallagher claims that "when I see the other's body moving in a certain way, I have a kinesthetic-proprioceptive sense of what that is like" (Gallagher 2005b, pp. 102, my emphasis). One way of taking this would be to argue that when one observes a bodily movement, one thereby enjoys an experience the phenomenal character of which is identical to that of the proprioceptive experience appropriate to that movement type. ${ }^{46}$ Such a claim, it might be thought, gives us reason to believe that we have one, rather than two, concepts of the movement type since experiencing another's behaviour is experientially just like experiencing one's own. I must admit to finding this view somewhat baffling since, so it seems to me, the visual experience of another person clapping their hands is manifestly different in phenomenal character to the proprioceptive experience enjoyed when one does the same. In any case, one way of testing such a claim would be to determine whether there is anything in the character of the visual and proprioceptive experiences in question that could motivate a question as to whether these were just the same bodily movements being experienced. If the phenomenal character were really identical, the answer would have to be negative. ${ }^{47}$ This is for the reason that phenomenal characters are individuated in much the same way as Fregean senses. ${ }^{48}$ However, I take it that a negative answer is highly counterintuitive here. In learning a complex dance move by observing an instructor, it can be perfectly rational for me to wonder whether the move I am performing is the same as the move I am observing. This is one of the things that make it such a difficult thing to do. ${ }^{49}$ If this is right, the strategy is implausible in this case.

A different way to respond to the argument from conceptual connections is to argue that transitions between the sort of innately tied concepts that are being considered do, in fact, qualify as conceptual in the relevant sense. As Loar writes, with respect to shape concepts, "There are...general epistemological models of rationality that, when applied to innate cross-modal inferential tendencies, would

\footnotetext{
${ }^{46}$ Such a position would be, in some ways, analogous to the view of Molyneux's question taken by Campbell, according to which there is no "difference between visual and tactual experience of shape itself" (Campbell 1995, p. 301). Campbell's view is motivated by his "radical externalism". This is the view that the phenomenal character of an experience of shape is determined by the shape property of the experienced object. Since it is the same property experienced via both sight and touch, the experience of shape in these modalities share a single phenomenal character. The present suggestion concerning the experience of bodily movements need not, however, be based upon such an externalist account of phenomenal character. In fact, one might think that such a claim would be implausible in the current context since mirror neuron activity is selective for certain types of bodily behaviour only, and it would be surprising if externalism were true of the visual/proprioceptive experiences of intentional action but not of experiences of the bodily behaviours 'directed towards' absent objects.

${ }^{47}$ Cf. Campbell, on his radical externalist account of shape properties, writes that "insofar as we are externalist about the character of shape perception, then there is nothing in the character of experience itself to ground a doubt as to whether it is the same properties that are being perceived through vision as through touch" (Campbell 1995, p. 303).

48 See Loar (1995, p. 320).

${ }^{49}$ For some relevant and interesting results concerning dance, see Cross et al. (2006).
} 
count them as a priori rational" (Loar 1995, p. 321). Perhaps this is correct, although this is not the place to examine the range of 'general epistemological models of rationality'. In any case, in the present context, the concern is with the unity of concepts and only indirectly with the rationality of intermodal transitions. It is notable that the sort of account that Loar appears to find congenial is one according to which the relevant concepts (in his case shape concepts) are disunified "conceptual amalgams", composed of a number of distinct concepts which are unified at the conscious level but can be pulled apart in the imagination. ${ }^{50}$ In the context of Husserl's theory of intersubjectivity and the problem of perceived similarity, such a view would hold that the concept ego is a conceptual amalgam presenting an apparent unity that can, however, be pulled apart. This view cannot be used to solve the problem of perceived similarity since it involves giving up on the claim that the sense alter ego can be shown to be legitimate, at least as Husserl understands this for, on such an account, the sense ego in experiences as of an alter ego is not identical to the sense ego when applied to myself. This would follow, I take it, from the disunity of the sense lived body. And a disunified lived body is all that the conceptual amalgam view would give us.

What is needed to adequately respond to the argument from conceptual connections is an account of concepts of bodily behaviours, and thus of the lived body, according to which the concept applicable purely on the basis of visual experience really is identical to the concept applicable purely on the basis of proprioceptive experience. Further, such an account, if it is to be related to the naturalisation of Husserl suggested by Gallagher's comments, should draw upon the existence of an intermodal code for representing both visual and proprioceptive information. Such an account cannot simply identify the tokening of the concept with the relevant mirror neuron activity for this would entail that the mirror system should be active when one merely thinks using the concept. But there is no evidence for this. So, an account must postulate a relation, weaker than identity, between patterns of mirror neuron activity and the tokening of perceptually derived concepts of bodily behaviours. In the absence of such an account, we will have no reason to suppose that the existence of a sub-personal intermodal code can solve the problem of perceived similarity and thus show that Husserl's account of intersubjectivity really can legitimate the sense alter ego. ${ }^{51}$

\section{Conclusion}

The account of intersubjectivity offered by Husserl in the fifth Cartesian Meditation falls foul of the problem of perceived similarity. At first appearance, empirical evidence in favour of an intermodal code common to vision and proprioception solves the problem at the expense of both the phenomenological and eidetic reductions. However, this is not the case. An account is lacking of concepts of bodily behaviours

\footnotetext{
$\overline{{ }^{50} \text { See Loar (1995, p. 324, fn. 1). }}$.

${ }^{51}$ I leave it open as to whether such an account of concepts of bodily behaviours must include some a priori element. An answer to this question awaits an adequate account of the relation between observational concepts and a priori entitlement.
} 
that entails that the concept applicable purely on the basis of vision is identical to that applicable purely on the basis of proprioception. I cannot argue here that such an account is not possible. Rather, I leave it as a challenge. What seems clear is that the postulation of an intermodal code common to vision and proprioception will not, in and of itself, solve the problem of perceived similarity. The intermodal code account is consistent with a disunified concept of the lived body and thus a disunified concept of the ego. For this reason, in the absence of an account of observational concepts of bodily behaviours, the naturalised version of Husserl's transcendental theory of intersubjectivity fails to count as a theory of intersubjectivity at all. ${ }^{52}$

\section{References}

Anisfeld, M., Turkewitz, G., \& Rose, S. A. (2001). No compelling evidence that newborns imitate oral gestures. Infancy, 2, 111-122.

Borg, E. (2004). If mirror neurons at the answer, what was the question? Journal of Consciousness Studies, 14, 5-19.

Campbell, J. (1995). Molyneux's Question. Philosophical Issues, 7, 301-318.

Cross, E. S., de C. Hamilton, A. F., \& Grafton, S. T. (2006). Building a motor simulation de novo: Observation of dance by dancers. Neuroimage, 31, 1257-1267.

Davidson, D. (1987). Knowing one's own mind. Proceedings and Addresses of the American Philosophical Association. Reprinted in Davidson, Subjective, Intersubjective, Objective (pp.1538). Oxford: Clarendon.

Evans, G. (1982). The varieties of reference (edited by J. McDowell). Oxford: Oxford University Press.

Evans, G. (1985). Molyneux's Question, in his Collected Papers (pp. 364-399). Oxford: Clarendon.

Fadiga, L., Fogassi, L., Pavesi, G., \& Rizzolatti, G. (1995). Motor facilitation during action observation: A magnetic stimulation study. Journal of Neurophysiology, 73(6), 2608-2611.

Gallagher, S. (2005a). How the body shapes the mind. Oxford: Clarendon.

Gallagher, S. (2005b). Phenomenological contributions to a theory of social cognition. Husserl Studies, 21, 95-110.

Gallagher, S., \& Meltzoff, A. N. (1996). The earliest sense of self and others: Merleau-Ponty and recent developmental studies. Philosophical Psychology, 9, 213-236.

Gergely, G. (2004). The development of understanding self and agency. In U. Goswami (Ed.), Blackwell handbook of childhood cognitive development. Oxford: Blackwell.

Henrich, D. (1989). Kant's notion of a deduction and the methodological background of the first critique. In E. Forster (Ed.), Kant's transcendental deductions (pp. 29-46). Stanford: Stanford University Press.

Husserl, E. (1960). Cartesian Meditations: An introduction to phenomenology (translated by D. Cairns). The Hague: Martinus Nijhoff.

Husserl, E. (1962). Phenomenological psychology, lectures summer semester 1925 (translated by J. Scanlon). The Hague: Martinus Nijhoff.

Husserl, E. (1982). Ideas pertaining to a pure phenomenology and to a phenomenological philosophy, first book: General introduction to a pure phenomenology (translated by F. Kersten). Dordrecht: Kluwer.

Husserl, E. (1989). Ideas pertaining to a pure phenomenology and to a phenomenological philosophy, second book: Studies in the phenomenology of constitution (translated by $R$. Rojcewicz \& $A$. Schuwer). Dordrecht: Kluwer.

Jacob, P. (2008). What do mirror neurons contribute to human social cognition? Mind and Language, 23, $190-223$.

\footnotetext{
$\overline{52}$ I began working on this material as a research fellow with the AHRC Transcendental Philosophy and Naturalism project, based at the University of Essex. Essex was an excellent place to think about transcendental intersubjectivity, and I profited from many fruitful discussions with a number of people there. Thanks also to audiences in both Manchester and London. Special thanks to Sebastian Gardner, Anil Gomes, Wayne Martin, Joseph Schear, Barry Smith, Ernie Sosa, Bob Stern, Ann Whittle and two anonymous referees for Phenomenology and the Cognitive Sciences. Finally, a great debt of thanks is owed to Mark Sacks, whose combination of sharp criticism and warm encouragement is much missed.
} 
Jones, S. S. (1996). Imitation or exploration? Young infants' matching of adults' oral gestures'. Child Development, 67, 1952-1969.

Jones, S. S. (2005). The role of mirror neurons in imitation. In S. Hurley \& N. Chater (Eds.), Perspectives on imitation: from cognitive neuroscience to social science, vol. 1 (pp. 205-210). Cambridge: MIT Press.

Jones, S. S. (2006). Exploration or imitation? The effect of music on 4-week-old infants' tongue protrusions. Infant Behavior and Development, 29, 126-130.

Keysers, C., \& Perrett, D. I. (2004). Demystifying social cognition: A Hebbian perspective. Trends in Cognitive Science, 8, 501-507.

Lee, N.-I. (2002). Static-phenomenological and genetic-phenomenological concept of primordiality in Husserl's fifth Cartesian Meditation. Husserl Studies, 18, 165-183.

Legerstee, M. (2005). Infants' sense of people: precursors to a theory of mind. Cambridge: Cambridge University Press.

Loar, B. (1995). Comments on John Campbell, 'Molyneux's Question'. Philosophical Issues, 7, 319-324.

Locke, J. (1975). An essay concerning human understanding (edited by P. H. Nidditch). Oxford: Clarendon.

Martin, M. G. F. (1995). Bodily awareness: A sense of ownership. In J. L. Bermúdez, A. Marcel \& N. Eilan (Eds.), The body and the self (pp. 267-289). Cambridge: MIT Press.

Meltzoff, A. N. (1995). Understanding the intentions of others: Reenactment of intended acts by 18month-old children. Developmental Psychology, 31, 838-850.

Meltzoff, A. N., \& Borton, R. W. (1979). Intermodal matching by human neonates. Nature, 282, 403-404.

Meltzoff, A. N., \& Moore, M. K. (1977). Imitation of facial and manual gestures by human neonates. Science, $198,75-78$.

Meltzoff, A. N., \& Moore, M. K. (1997). Explaining facial imitation: A theoretical model. Early Development and Parenting, 6, 179-192.

Merleau-Ponty, M. (1962). Phenomenology of perception (translated by C. Smith). London: Routledge.

McGinn, C. (1984). What is the problem of other minds? Proceedings of the Aristotelian Society, Supplementary, 58, 119-137.

Morgan, M. J. (1977). Molyneux's Question: Vision, touch and the philosophy of perception. Cambridge: Cambridge University Press.

Mulligan, K. (1995). Perception. In B. Smith \& D. W. Smith (Eds.), Cambridge companion to Husserl (pp. 168-238). Cambridge: Cambridge University Press.

Muthukumaraswamy, S., Johnson, B., \& McNair, N. (2004). Mu rhythm modulation during observation of an object-directed grasp. Cognitive Brain Research, 19, 195-201.

Oberman, L., McCleary, J., Ramachadran, V., \& Pineda, J. (2007). EEG evidence for mirror neuron activity during the observation of human and robot actions: Toward an analysis of the human qualities of interactive robots. Neurocomputing, 70, 2194-2203.

Peacocke, C. (1984). Consciousness and other minds. Proceedings of the Aristotelian Society, Supplementary, 58, 97-117.

Reynaert, P. (2001). Intersubjectivity and naturalism-Husserl's Fifth Cartesian Meditation revisited. Husserl Studies, 17, 207-216.

Rizzolatti, G., Fogassi, L., \& Gallese, V. (2001). Neurophysiological mechanisms underlying the understanding and imitation of action. Nature Reviews Neuroscience, 2, 661-670.

Scheler, M. (2008). The nature of sympathy (translated by P. Heath). New Brunswick: Transaction.

Schmuckler, M. A., \& Fairhall, J. L. (2001). Visual-proprioceptive intermodal perception using point light displays. Child Development, 72, 949-962.

Schutz, A. (1970). The problem of transcendental intersubjectivity in Husserl, in his, Collected Papers III: Studies in Phenomenological Philosophy (pp. 51-91). The Hague: Martinus Nijhoff.

Smith, A. D. (2003). Husserl and the Cartesian Meditations. London: Routledge.

Smith, J. (2006). Bodily awareness, imagination and the self. European Journal of Philosophy, 14, 49-68.

Streri, A., \& Gentaz, E. (2003). Cross-modal recognition of shape from hand to eyes in human newborns. Somatosensory \& Motor Research, 20, 13-18.

Umiltà, M. A., Kohler, E., Gallese, V., Fogassi, L., Fadiga, L., Keysers, C., et al. (2001). I know what you are doing: a neurophysiological study. Neuron, 32, 91-101.

Welsh, T. (2006). Do neonates display innate self-awareness? Why neonatal imitation fails to provide sufficient grounds for innate self- and other-awareness. Philosophical Psychology, 19, 221-238.

Wittgenstein, L. (1953). Philosophical investigations. Oxford: Blackwell.

Zahavi, D. (2001). Husserl and transcendental intersubjectivity: A response to the linguistic-pragmatic critique. Athens: Ohio University Press.

Zahavi, D. (2003). Husserl's phenomenology. Stanford: Stanford University Press. 